Article

\title{
Associations of Physical Activity, Sleep Quality and Cardiovascular Risk Factors in University Students
}

\author{
N. Z. M. Saat ${ }^{1, * \mathbb{D}}$, Siti Aishah Hanawi ${ }^{2}$, Nor M. F. Farah ${ }^{3} \mathbb{D}$, Hazilah Mohd Amin ${ }^{2}$, Hazlenah Hanafiah ${ }^{4}$ \\ and Thavamalar Selvaraj ${ }^{1}$
}

check for updates

Citation: Saat, N.Z.M.; Hanawi, S.A.; Farah, N.M.F.; Mohd Amin, H.; Hanafiah, H.; Selvaraj, T. Associations of Physical Activity, Sleep Quality and Cardiovascular Risk Factors in University Students. Sustainability 2021, 13, 11806. https://doi.org/ $10.3390 /$ su132111806

Academic Editors: José

Carmelo Adsuar Sala and

Carlos Salavera

Received: 21 July 2021

Accepted: 20 October 2021

Published: 26 October 2021

Publisher's Note: MDPI stays neutral with regard to jurisdictional claims in published maps and institutional affiliations.

Copyright: (c) 2021 by the authors. Licensee MDPI, Basel, Switzerland. This article is an open access article distributed under the terms and conditions of the Creative Commons Attribution (CC BY) license (https:/ / creativecommons.org/licenses/by/ $4.0 /)$.
1 Biomedical Science Programme, Centre for Community Health Studies, Faculty of Health Sciences, Universiti Kebangsaan Malaysia, Kuala Lumpur 50300, Malaysia; malar2729@yahoo.com

2 SOFTAM, Faculty of Information Science and Technology, Universiti Kebangsaan Malaysia, Bangi 43600, Malaysia; ctaishah@ukm.edu.my (S.A.H.); hazlilah@ukm.edu.my (H.M.A.)

3 Centre for Community Health Studies, Faculty of Health Sciences, Universiti Kebangsaan Malaysia, Kuala Lumpur 50300, Malaysia; norfarah@ukm.edu.my

4 Faculty of Computer and Mathematical Science, Universiti Teknologi MARA Sabah Branch, Kota Kinabalu Campus, Sabah 88997, Malaysia; hazlenahh@uitm.edu.my

* Correspondence: nurza@ukm.edu.my

\begin{abstract}
Physical activity is associated with enhanced sleep quality and optimal body composition, as well as a reduction in cardiovascular risk factors in the general population. Although earlier research has established a link between physical exercise and excellent sleep quality as well as an optimum BMI in adults, little is known about the relationship in the young adult populations. The purpose of this study is to discover if there is a relationship between sleep quality, blood pressure, waist circumference, socio-demographic variables with physical activity among young adult in Kuala Lumpur. A cross-sectional sample of 120 university students was recruited for this study. Physical activity and sleep quality were assessed using the International Physical Activity Questionnaire and the Pittsburgh Sleep Quality Index, respectively. Blood pressure, Body mass index, and waist circumference were also measured. Approximately $36 \%$ of university students engage in moderate to vigorous physical exercise. The average physical activity was $2430.37 \pm 2509.16$ MET-minutes each week, which meets the minimal need. The median difference in MET-minutes per week between gender was not significant, with males having greater MET than females $(p>0.05)$. However, there was no statistically significant variation in MET-minutes each week between study year and mode of transportation. $(p>0.05)$. Approximately $40.3 \%$ of university students were classified as having good sleep quality. The average sleep quality is $5.37 \pm 2.38$, indicating that the students have slightly a poor sleep quality. There was no statistically significant variation in sleep score between gender, year of study, and mode of transportation $(p>0.05)$. The waist circumference (WC) has a significant relationship with body mass index (BMI), systolic blood pressure (SBP), and diastolic blood pressure (DBP). According to multinomial logistic regression, there was a significant association between level of physical activity (PA) and BMI and year of study when comparing moderate and low PA. Physical activity is essential because it may alter a young adult's lifestyle, encouraging active commuting to work or other short-distance destinations. Attention must be given to this particular population to encourage regular and sustainable participation in physical activity to achieve lifelong health benefits. Other variables, such as body fat, energy intake, stress level and muscle mass, can also be examined for future research.
\end{abstract}

Keywords: physical activity; sleep quality; body mass index; university student

\section{Introduction}

Globalization and sophisticated technology have resulted in a decrease in public participation in physical exercise. Noncommunicable diseases such as hypertension [1] hypercholesterolemia, heart disease, and others have been associated with a sedentary 
lifestyle [2]. Noncommunicable diseases were projected to be the cause of 71 percent of the 51 million deaths worldwide in 2016, with cardiovascular disease contributing to 17 million deaths [3].

The prevalence of cardiovascular diseases (CVD) rose in 2015 compared to 2011, according to the National Health and Morbidity Survey (NHMS) IV report. Obesity (11.2 percent in 2011 vs. $13.4 \%$ in 2015), hypertension (32.7 percent in 2011 vs. 30.3 percent in 2015), and hypercholesteremia (35.1 percent in 2011 vs. $47.7 \%$ in 2015) were the primary causes of increasing prevalence among adults aged 18 and above [4]. Previous research of students found that the transition from high school to college has an impact on their daily activities [5]. This is related to a sedentary lifestyle, since students spend most of their time studying and performing assignments, rather than participating in sports and curricular activities [6].

Studies have associated a sedentary lifestyle with a higher body mass index (BMI), with a modest rise in BMI and waist circumference (WC) among male students when they move from high school to college [7]. According to a study conducted in Greece, 13\% of university students are at risk of hypertension, and $17 \%$ are overweight. Body mass index (BMI) was strongly related to waist circumference (WC) among young people in Ghana [8]. Students who are overweight or obese have a higher risk of acquiring hypertension [9]. Higher BMI and blood pressure were found to increase the risk of cardiovascular disease mortality in adults in a previous longitudinal research in Finland [10]. Higher levels of physical activity were associated with a 75\% decreased risk of cardiovascular disease and death [11].

The physical activity led to a restful night's sleep. Previous research on Saudi students found a connection between physical activity and sleep quality. According to the same study, 68.5\% of sedentary students had poor sleep quality [12]. Another research of university student in China found that increased physical activity and less time spent on devices reduced the likelihood of poor sleep quality [13]. Another research in Spain used the physical activity assessment tool to evaluate the frequency and duration of physical exercise among university students. According to the study, students who do not participate in adequate physical activity are twice as likely to have poor sleep quality as those who do [14].

Despite a growing awareness that young people who do not engage in physical exercise have a higher risk of developing cardiovascular disease, little research has been done on the relationship between sleep quality, physical activity, and BMI in young adults. Physical activity in one's everyday life can help to lower the chance of developing CVD. Adults should engage in 150 min of moderate physical activity or 75 min of intense physical activity every week, according to the Ministry of Health Malaysia [15]. Young people, on the other hand, have a lower inclination to engage in physical exercise as a result of their sedentary lifestyle [7], particularly those in colleges and universities where they must focus more on academics to get excellent results. Therefore, it is critical for young adults to engage in physical activity, as this is in line with the Ministry of Health's objective to get Malaysians active in order to meet the Global NCD Target of reducing NCD and sedentary by 2025 [16].

There is currently a limited research among young people in metropolitan areas to give a wider grasp of the associations between physical activity and socio-demographic status among young adults. As a result, the purpose of this study is to determine the level of physical activity and its associations with socio-demographic status, anthropometry measures, blood pressure, and sleep quality. Perhaps the outcomes of this study will inspire university administrators to explore methods to encourage students to engage in physical exercise. 


\section{Materials and Methods}

\subsection{Study Designs and Study Participants}

This is a cross-sectional study among university students. A convenience sampling method was used to obtain the sample that represented the male and female students. The sampling frame consisted of student the first year until the final year that stayed on campus. All respondents that was selected was given informed consent to participate in this study. Participants signed an informed consent form, and some also gave verbal consent. Students between the ages of 20 and 44 were requested to participate in this study. Individuals with chronic illnesses, who were taking medication for a sleep problem, or who were disabled were excluded from this study. The ethics committee of Universiti Kebangsaan Malaysia gave its permission to this study. This study was approved by the Secretariat Ethical Committee Universiti Kebangsaan Malaysia (JEP-2018-209).

\subsection{Power and Sample Size Calculation}

The sample size of the study was calculated using the formula $n=(Z)^{2} p(1-p) / \Delta^{2}[17]$. $p$ is the prevalence of moderate and vigorous physical activity among young adults which is $67.9 \%$ [5], with $\mathrm{z}=1.96, \Delta=8 \% n=(1.96)^{2} 0.68(1-0.68) /(0.08)^{2}=130$. Therefore 130 participants were required for this study. The power of this study was $80 \%$ based on the GPower (G ${ }^{*}$ Power $^{\circledR}$ Version 3, Berlin, Germany), with an effect size of 0.27 [18].

\subsection{Assessment for Blood Pressure and Anthropometry}

The BMI was determined using height and weight data taken from the participants. A Seca Bodymeter 206 (Seca, Hamburg, Germany) was used to determine the height, while a GTE Electronic Digital Scale (GTE, Beijing, China) was used to determine weight. To achieve an accurate figure, the items in the participant's pockets and shoes were removed before these measures were collected. Following the collection of these two measures, the BMI was computed using the following formula: weight in kilograms divided by height squared $\left(\mathrm{kg} / \mathrm{m}^{2}\right)$ [19]. Waist circumference (WC) was measured in $\mathrm{cm}$ using a Lufkin (Apex, New York, NY, USA) measuring tape. The measurement of WC was taken at the midpoint between the last palpable rib and top of the iliac crest. All measurements were repeated twice, with the average result reported $[20,21]$. The data were analyzed using cutoffs points for Asians $90 \mathrm{~cm}$ in men and $80 \mathrm{~cm}$ in women [4,20] The categories of BMI was classified into underweight $\left(18.5 \mathrm{~kg} / \mathrm{m}^{2}\right)$, normal $\left(18.55\right.$ until $\left.22.99 \mathrm{~kg} / \mathrm{m}^{2}\right)$, overweight (23.0 until $27.49 \mathrm{~kg} / \mathrm{m}^{2}$ ) and obese $\left(27.5\right.$ until $\left.34.99 \mathrm{~kg} / \mathrm{m}^{2}\right)$ [4,22].

A digital sphygmomanometer (Terumo Corporation, Tokyo, Japan) was used to measure the systolic (SBP) and diastolic (DBP) blood pressure with an appropriate cuff size while the participant was sitting and resting. The right hand is used to take blood pressure readings. The BMI and blood pressure were used in a previous study among adults [4]. SBP was less than $120 \mathrm{mmHg}$, and DBP was less than $80 \mathrm{mmHg}$, which was considered normal [23].

\subsection{Assessment for Physical Activity}

The International Physical Activity Questionnaire (IPAQ) is used to assess physical activity levels. It is made up of seven questions that must be answered. The questions in this survey are about three different sorts of activities that are done in all three domains and sitting. Walking, moderate-intensity activities, and high-intensity activities were all examined. The length of exercise is assessed in minutes per day and the frequency of activity is measured once a week. Each question can provide a separate score for each domain as well as the total of all domains' scores to determine physical activity level. Following the collection of data, the overall activity is computed using the energy requirements for each of the Metabolic Equivalent Tasks (METs). More than $600 \mathrm{~min}$ of MET per week is suggested for each individual [24]. The IPAQ has been utilized in a variety of studies in the past $[25,26]$. 
According to the IPAQ recommendations, physical activity levels were categorized into three categories: low (600 MET-minutes/week), moderate (600-3000 MET-minutes/week), and high (3000 MET-minutes/week) [20]. The total IPAQ score was used to identify moderate-to-vigorous physical activity, with the categories sedentary (100 counts $/ \mathrm{min}$ ), light (101-1951 counts/min), moderate (1952-5724 counts/min), and vigorous (5725 counts/min) being used [24].

\subsection{Assessment for Sleep Quality}

The Pittsburgh Sleeping Quality Index questionnaire was used to determine sleep quality (PSQI). For each participant, this questionnaire may compare good sleep quality to bad sleep quality. Subjective sleep quality, sleep latency, sleep length, sleep efficiency, sleep disruption, usage of sleep medicine, and daytime dysfunction are all included in this questionnaire. The results for the seven components were combined to get global PSQI scores, which may be used to evaluate the quality of sleep among students. A total score of five or more shows that the student is experiencing sleep issues and is classified as having poor sleep quality [27]. We utilized the PSQI, which has previously been used to assess sleep quality in university students [25]. All of the measurements were carried out by a research student who had been trained by university experts in the area.

\subsection{Statistical Analysis}

In the study data were analyzed using IBM SPSS Statistics for Windows, version 20 (IBM Corp., Armonk, NY, USA). Descriptive analysis of the socio-demographic factors such as gender, type of transportation to campus, and age group were presented as percentages. Meanwhile the continuous assessment such as the systolic blood pressure, diastolic blood pressure, waist circumference, body mass index was shown as mean + standard deviation (SD. Mann-Whitney and Kruskal Wallis were used to compare physical activity level by using MET ( $\mathrm{min} /$ week) between socio-demographic factors due to data MET (min/week) was not normally distributed. Meanwhile, the $t$ test and one-way ANOVA were developed to evaluate sleep scores across sociodemographic variables. Spearman correlation was used to correlate between physical activity with anthropometric measurements and sleep quality. Multinomial logistic regression was done to determine the relationship between the level of physical activity (low, moderate, high) with BMI, blood pressure, sleep quality score, gender and year of study. The intercept and parameter estimate for each BMI, in relation to PA category were examined using piecewise regression analysis according to a break point of BMI category.

\section{Results}

The participants in this study were divided into two equal groups of 60 male and 60 female students. According to Table 1,79.2\% of participants were between the ages of 19 and 22, while $16.8 \%$ were older than 22 . The study's participants were of different races, but Malays accounted for $63.3 \%$ of the total, followed by Chinese (20.8\%), Indians (13.3\%), and others $(2.5 \%)$. Bus, walking, and automobile or motorbike were the three modes of transportation utilized by participants to get to school. Buses were utilized by $66.7 \%$ of the participants as their primary mode of transportation to campus, followed by automobiles or motorbikes (17.5\%) and walking (15.8\%).

Anthropometry and blood pressure readings are shown in Table 2. BMI and WC are two types of anthropometric data. Based on this study, the average WC for the participants was $77.83 \pm 10.19 \mathrm{~cm}$ and this was within the normal range. BMI was at an average of $22.63 \pm 4.60 \mathrm{~kg} / \mathrm{m}^{2}$ and this indicates that participants were categorized as normal. The average for underweight was $17.49 \pm 0.52$, normal $21.23 \pm 1.67$, overweight is $26.99 \pm 2.05$ while obese was $35.41 \pm 3.03$. 
Table 1. Characteristics of the participants (\%).

\begin{tabular}{cccc}
\hline \multirow{2}{*}{ Parameters } & & $\boldsymbol{n}$ & Percentage \\
\hline \multirow{2}{*}{ Gender } & Male & 60 & 50 \\
& Female & 60 & 50 \\
\hline \multirow{3}{*}{ Transportation } & Bus & 80 & 66.7 \\
& Car/Motorcycle & 21 & 17.5 \\
& Walking & 19 & 15.8 \\
\hline \multirow{3}{*}{ Year of study } & 1 & 30 & 25 \\
& 2 & 30 & 25 \\
& 3 & 30 & 25 \\
Age group & 4 & 30 & 25 \\
& $19-22$ & 99 & 79.2 \\
& $>22$ & 21 & 16.8 \\
\hline \multirow{2}{*}{ Races } & Malay & 99 & 79.2 \\
& Chinese & 25 & 20.0 \\
& Indian & 16 & 12.8 \\
\hline
\end{tabular}

Table 2. Anthropometric measurement and blood pressure in mean \pm standard deviation (SD) for overall participants.

\begin{tabular}{|c|c|c|c|}
\hline \multicolumn{2}{|c|}{ Measurement } & \multirow{2}{*}{$\frac{n}{120}$} & \multirow{2}{*}{$\frac{\text { Mean } \pm \text { SD }}{77.83 \pm 10.19}$} \\
\hline & Overall & & \\
\hline Waist Circumference $(\mathrm{cm})$ & $<80 \mathrm{~cm} /<90 \mathrm{~cm}$ & 95 & $76.21 \pm 9.57$ \\
\hline & $>80 \mathrm{~cm} />90 \mathrm{~cm}$ & 25 & $85.29 \pm 11.01$ \\
\hline \multirow{4}{*}{ BMI $\left(\mathrm{kg} / \mathrm{m}^{2}\right)$} & Underweight & 13 & $17.49 \pm 0.52$ \\
\hline & Normal & 81 & $21.23 \pm 1.67$ \\
\hline & Overweight & 18 & $26.99 \pm 2.05$ \\
\hline & Obese & 8 & $35.41 \pm 3.03$ \\
\hline \multirow{4}{*}{$\begin{array}{l}\text { Systolic Blood Pressure } \\
\text { Diastolic Blood Pressure }\end{array}$} & Normal & 120 & $112.76 \pm 11.19$ \\
\hline & $(<120 \mathrm{mmHg} / 80 \mathrm{mmHg})$ & 120 & $67.98 \pm 9.51$ \\
\hline & High & 104 & $110.78 \pm 9.23 / 66.63 \pm 9.03$ \\
\hline & $(>120 \mathrm{mmHg} / 80 \mathrm{mmHg})$ & 16 & $130.06 \pm 6.33 / 76.69 \pm 8.02$ \\
\hline Total MET (min/week) & & 120 & $2535.90 \pm 2303.82$ \\
\hline Sitting (hour/day) & & 120 & $4.04 \pm 2.73$ \\
\hline
\end{tabular}

For blood pressure, the average systolic blood pressure was at $112.76 \pm 11.19 \mathrm{mmHg}$ and diastolic blood pressure was normal with $67.98 \pm 9.51 \mathrm{mmHg}$. Systolic blood pressure of $110.78 \pm 9.23$ and diastolic blood pressure of $66.63 \pm 9.03$ are indicated as normal. The average level of physical activity among students is also shown in Table 2. Based on the information gathered, the average MET value is $2535.90 \pm 2303.82 \mathrm{~min} /$ week and this value reached the recommended time for physical activity which were a minimum of $600 \mathrm{MET} /$ week. The average sitting time was $4.04 \pm 2.73 \mathrm{~h}$ per day.

According to Figure 1, the low activity physical activity category made up $20 \%$ of the university students, whereas moderate and light active students made up $80 \%$. In the category of sleep quality, $58.7 \%$ had poor sleep quality and 40.3 percent had good sleep quality. According to Table 2, the systolic blood pressure and diastolic blood pressure were in the normal range for all levels of physical activity. Meanwhile BMI was in the normal weight category for low through high physical activity levels. Table 3 further presented the descriptive results of SBP, DBP, WC, and BMI based on physical activity level. On average, SBP, DBP, BMI, and WC were slightly different between low, moderate, and high physical activity, according to the findings. 


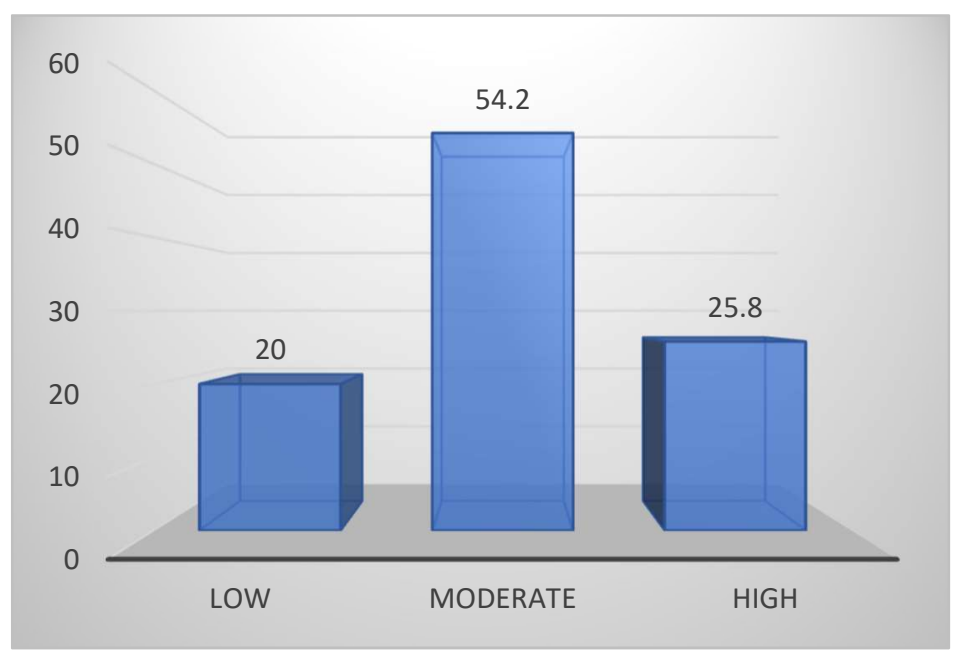

Figure 1. The percentage category of physical activity.

Table 3. The mean \pm SD of systolic blood pressure, diastolic blood pressure, waist circumference, body mass index and score of sleep quality according to the level of physical activity.

\begin{tabular}{cccc}
\hline & \multicolumn{3}{c}{ Level of Physical Activity } \\
\hline Low $(\boldsymbol{n}=\mathbf{2 4})$ & Moderate $(\boldsymbol{n}=\mathbf{6 5})$ & High $(\boldsymbol{n}=\mathbf{3 1})$ \\
\hline SBP $(\mathrm{mm} \mathrm{Hg})$ & $111.04 \pm 10.49$ & $113.49 \pm 11.28$ & $112.65 \pm 11.71$ \\
DBP $(\mathrm{mm} \mathrm{Hg})$ & $67.54 \pm 9.44$ & $68.51 \pm 9.61$ & $67.19 \pm 9.62$ \\
WC $(\mathrm{cm})$ & $79.06 \pm 11.14$ & $76.29 \pm 9.35$ & $80.09 \pm 10.89$ \\
BMI $\left(\mathrm{kg} / \mathrm{m}^{2}\right)$ & $23.45 \pm 4.99$ & $21.76 \pm 4.07$ & $23.83 \pm 5.07$ \\
PSQI & $5.05 \pm 1.73$ & $5.35 \pm 2.49$ & $5.65 \pm 2.60$ \\
MET (min/week) & $327.92 \pm 168.10$ & $1587 \pm 785.78$ & $5677 \pm 2395.79$ \\
\hline
\end{tabular}

Based on Table 4, according to the Mann- Whitney test and Kruskal Wallis test, factor gender, year of study and type of transportation factors had no significantly different effect on the total MET of physical activity. Males showed the highest mean of $2930.48 \pm 3055.05 \mathrm{~min}$. while females showed $1853.13 \pm 1339.16 \mathrm{~min}$. Year 1 showed the highest mean of MET compared to other years of study. The mean of year 1 was $3298.03 \pm 3053.48$, year 2, $2797.43 \pm 2776.90$, year $3,1575.77 \pm 1492.45$ and in year $41896.00 \pm 1616.33$. For the type of transportation, car/motorcycle showed a mean of $2351.48 \pm 2278.10 \mathrm{~min}$, bus $2268.64 \pm 2320.31 \mathrm{~min}$ and walking $2955.00 \pm 2933.56 \mathrm{~min}(p>0.05)$.

Table 4. Comparison of median and IQR of physical activity (total MET min/week) between gender, year of study and type of transportation.

\begin{tabular}{ccccc}
\hline & & N & Median & IQR \\
\hline \multirow{2}{*}{ Gender $^{\mathbf{a}}$} & Male & 60 & 1784 & 3565 \\
& Female & 60 & 1308 & 2070 \\
\hline \multirow{2}{*}{ Year $^{\mathbf{b}}$} & 1 & 30 & 1902 & 4051 \\
& 2 & 30 & 2425 & 3408 \\
& 3 & 30 & 1053 & 1626 \\
Type of transportation $^{\mathbf{b}}$ & 4 & 30 & 1290 & 2270 \\
& Car/Motorcycle & 21 & 1498 & 3181 \\
& Bus & 80 & 1287 & 2241 \\
& Walking & 19 & 1498 & 3181 \\
\hline
\end{tabular}

${ }^{a}$ Mann-Whitney test. ${ }^{b}$ Kruskal Wallis test. 
When comparing sleep quality scores between genders, years of study, and modes of transportation, there were no significant differences in sleep quality (data not shown). Both sexes showed poor sleep quality, but males recorded a higher average of $5.43 \pm 2.47$ compared to females $(5.30 \pm 2.30)$. For the year of study, only year 3 showed a good sleep quality score of $5.00 \pm 2.66$ compared to year $15.53 \pm 2.66$, year $25.13 \pm 2.10$ while year 4 recorded the highest average of $5.80 \pm 2.62$. For the type of transportation, cars/motorcycle recorded a high average of $5.95 \pm 3.03$ followed by walking $5.32 \pm 2.50$ and bus $5.23 \pm 2.16$. According to Table 5, based on Spearman rho correlation there was a significant correlation SBP with BMI $(r=0.277, p<0.05)$ and with DBP $(r=0.575, p<0.01)$ and WC $(r=0.408$, $p<0.01)$. There was significant positive correlation between DBP with BMI $(\mathrm{r}=0.408$, $p<0.001)$, WC with DBP $(\mathrm{r}=0.224, p<0.05)$, and WC $(\mathrm{r}=0.316, p<0.001)$. Furthermore, there was significant correlation between BMI and WC $(r=0.824, p<0.001)$. SBP and DBP elevated with increasing BMI and WC, according to the findings. However, there was no significant correlation between MET with other variables $(p>0.05)$.

Table 5. Correlation between MET with SBP, DBP, BMI, WC, PSQI.

\begin{tabular}{ccccccc}
\hline Parameter & MET & SBP & DBP & BMI & WC & PSQI \\
\hline MET & & 0.037 & -0.025 & 0.098 & 0.067 & 0.344 \\
SBP & 0.037 & & $0.577^{* *}$ & $0.277^{* *}$ & $0.408^{* *}$ & 0.191 \\
DBP & -0.025 & $0.575^{* *}$ & & $0.224^{*}$ & $0.316^{* *}$ & 0.021 \\
BMI & 0.098 & $0.277^{* *}$ & $0.224^{*}$ & & $0.824^{* *}$ & -0.028 \\
WC & 0.067 & $0.408^{* *}$ & $0.316^{* *}$ & $0.824^{* *}$ & & -0.008 \\
PSQI & 0.344 & 0.191 & 0.021 & -0.028 & -0.008 & \\
\hline
\end{tabular}

${ }^{*}=$ Significance subscale $(p<0.05),{ }^{* *}=$ significance subscale $(p<0.001)$.

Table 6 shows the relationship between the level of PA with antropometry, blood pressure and sleep quality according to multinomial logistic regression. The results shows that there was a significant association between level of PA with BMI, indicating a lower BMI among the moderate PA group compared to the low activity level group. Meanwhile comparing year 1 to year 4, 11.34 reported higher physical activity in the moderate PA group compared to a low PA level. Meanwhile year 1 had a high PA, 14.14 times higher compared to year 4 . The significant odds ratio difference between year 1 compared to year 4 may be due to chance because of the sampling method chosen in this study.

Table 6. The multinomial logistic regression between physical activity level with gender, SBP, DBP, BMI, year of study and quality of sleep score (PSQI).

\begin{tabular}{|c|c|c|c|c|c|c|}
\hline & Variables & Estimates & SE & Wald & $\begin{array}{l}\text { Odds } \\
\text { Ratio }\end{array}$ & $\begin{array}{c}95 \% \\
\text { Confidence } \\
\text { Interval }\end{array}$ \\
\hline \multirow{9}{*}{$\begin{array}{l}\text { Moderate } \\
\text { physical } \\
\text { activity }^{\text {a }}\end{array}$} & Intercept & -0.256 & 2.93 & & & \\
\hline & $\begin{array}{l}\text { Gender } \\
\text { (Male) }^{b}\end{array}$ & -0.514 & 0.52 & 0.99 & 0.59 & $0.22,1.64$ \\
\hline & PSQI & 0.052 & 0.12 & 0.21 & 1.05 & $0.84,1.32$ \\
\hline & SBP & 0.029 & 0.03 & 0.90 & 1.03 & $0.97,1.09$ \\
\hline & DBP & 0.004 & 0.03 & 0.01 & 1.06 & $0.94,1.07$ \\
\hline & BMI & -0.121 & 0.06 & 4.13 & 0.89 * & $0.79,0.99$ \\
\hline & Year (1) ${ }^{c}$ & 2.43 & 1.14 & 4.51 & $11.34^{*}$ & $1.21,106.52$ \\
\hline & Year (2) & 0.18 & 0.69 & 0.07 & 1.20 & $0.31,4.65$ \\
\hline & Year (3) & 0.25 & 0.64 & 0.15 & 1.28 & $0.37,4.44$ \\
\hline
\end{tabular}


Table 6. Cont.

\begin{tabular}{|c|c|c|c|c|c|c|}
\hline & Variables & Estimates & SE & Wald & $\begin{array}{l}\text { Odds } \\
\text { Ratio }\end{array}$ & $\begin{array}{c}95 \% \\
\text { Confidence } \\
\text { Interval }\end{array}$ \\
\hline \multirow[t]{9}{*}{$\begin{array}{l}\text { High physical } \\
\text { activity }^{\text {a }}\end{array}$} & Intercept & -1.05 & 3.27 & & & \\
\hline & $\begin{array}{l}\text { Gender } \\
\text { (Male) }^{b}\end{array}$ & 0.43 & 0.61 & 0.51 & 1.54 & $0.47,5.06$ \\
\hline & PSQI & 0.09 & 0.13 & 0.61 & 1.10 & $0.86,1.42$ \\
\hline & SBP & 0.02 & 0.04 & 0.32 & 1.01 & $0.95,1.09$ \\
\hline & DBP & -0.03 & 0.04 & 0.84 & 1.02 & $0.89,1.04$ \\
\hline & BMI & 0.01 & 0.06 & 0.02 & 1.10 & $0.89,1.14$ \\
\hline & Year $(1)^{c}$ & 2.65 & 1.20 & 4.87 & 14.14 * & $1.34,148.76$ \\
\hline & Year (2) & 1.12 & 0.78 & 2.12 & 3.05 & $0.67,13.73$ \\
\hline & Year (3) & -0.78 & 0.85 & 0.76 & 0.46 & $0.08,2.65$ \\
\hline
\end{tabular}

Model chi-square $=244.43,-2 \log$ likelihood $=240.87$, Pseudo $R^{2}$ (Nagelkerke) $=0.26 .{ }^{\text {a }}$ reference category is 1 (low physical activity). ${ }^{b}$ reference category is: 2 (female). ${ }^{\mathrm{c}}$ reference category is: 4 (year 4 ). ${ }^{*}=$ significance subscale $(p<0.05)$.

Piecewise regression results, with $B$ coefficient, standard error, odds ratio and $95 \%$ confidence interval were reported in Table 7 . The results indicated there was no significant relationship between level of PA with BMI for all category of BMI $(p>0.05)$.

Table 7. Piecewise regression intercept and parameter estimates according to category of BMI.

\begin{tabular}{|c|c|c|c|c|c|c|}
\hline BMI Category & Level of PA & Variables & B Coefficient & Standard Error & Odds Ratio & 95\% Confidence Interval \\
\hline \multirow{4}{*}{$\mathrm{BMI}<18.5$} & Moderate & Intercept & 12.59 & 35.75 & & \\
\hline & \multirow{3}{*}{ High } & BMI & -0.58 & 2.02 & 0.56 & $0.74,1.16$ \\
\hline & & Intercept & 14.20 & 39.25 & & \\
\hline & & BMI & -0.74 & 2.22 & 0.48 & $0.77,1.18$ \\
\hline \multirow{4}{*}{$18.5 \leq \mathrm{BMI} \leq 22.9$} & Moderate & Intercept & 2.53 & 3.74 & & \\
\hline & \multirow{3}{*}{ High } & BMI & -0.07 & 0.18 & 0.93 & $0.66,1.31$ \\
\hline & & Intercept & -3.51 & 4.47 & & \\
\hline & & BMI & 0.17 & 0.21 & 1.18 & $0.79,1.77$ \\
\hline \multirow{4}{*}{$23 \leq \mathrm{BMI} \leq 27.49$} & Moderate & Intercept & 39.41 & 21.82 & & \\
\hline & \multirow{3}{*}{ High } & BMI & -1.437 & 0.802 & 0.24 & $0.05,1.14$ \\
\hline & & Intercept & 43.372 & 23.073 & & \\
\hline & & BMI & -1.593 & 0.852 & 0.20 & $0.04,1.08$ \\
\hline \multirow{2}{*}{$27.5 \leq \mathrm{BMI} \leq 34.9$} & \multirow[t]{2}{*}{ Moderate } & Intercept & 5.186 & 13.749 & & \\
\hline & & BMI & -0.133 & 0.382 & 0.88 & $0.41,1.85$ \\
\hline
\end{tabular}

Dependent variable: Level of physical activity. Reference category: Low physical activity.

\section{Discussion}

The majority of the individuals in this study engaged in physical activities, regardless of whether they were low, medium, or high intensity. In this study $80 \%$ of students were in the moderate and vigorous physical activity category. The percentage of sedentary and low activity students was lower in this study compared to other studies. For example, it was 55\% in Turkey [28] and also higher in a Malaysian population study for young adults reported in 2015 [5]). Additionally, in this study students spent on average $4 \mathrm{~h}$ each day performing activities that require prolonged sitting, such as accessing the internet, doing assignments, and others. Previous research has found that students frequently engage in sedentary behaviors such as sitting, reclining, and limiting daily activity [29].

Furthermore, the findings also showed that physical activity was different across demographic variables such as gender, years of study, and mode of transportation. Male students were more active than female students in this study. A previous study among students in Ukraine showed that activity was on average 3863 MET min/week among 
male students, which is higher compared to the results in this study [30]. Nevertheless, the findings are comparable to those of earlier research among university students, which found that male students are more active than female students because males are more interested in athletic activities [31].

According to logistic regression, the difference between moderate and low PA was 11 times greater in year 1 compared to year 4 . Furthermore, the difference between year 1 and year 4 was 14 times in the area of high PA versus low PA. This is because students in their first year are more active than students in years two, three, and four. Because of the structure and the fact that each year's learning period is varied, the descriptive results of MET change according to the years of study. Lectures for first and second year students are usually shorter than those for third and fourth year students. Furthermore, first and second year students are more likely to participate in college events in order to earn merit points and stay in college for the duration of their studies [32]. The first and second year students also spend more time on campus attending classes, whereas third and fourth year students were most likely to spend more time doing industrial or clinical training, therefore were less likely to engage in physical activity. Previous research has also shown that first year students are more engaged in physical activity than students in later years of study [33]. In contrast, a study of medical students found that due to the course structure, there was a substantial variation in physical activity between years of study [34]. There was no significant difference in MET between modes of transportation in this research. This finding contrasts with a recent research that found a strong link between physical activity and transportation in Europe, Australia, and the United States, where older individuals have access to their own transportation, such as a vehicle, but young adults usually walk and cycle [35].

Most university students in Malaysia prefer to take the bus or other forms of transport to commute, which could be due to the hot and humid climate in Malaysia which makes walking or cycling uncomfortable. According to this study, the majority of students go to campus using some means of public transportation, like buses, which should be encouraged because utilizing public transportation reduces carbon emissions. It is critical for policymakers to encourage citizens to schedule an active commute to work, university, or school, such as walking to work on certain days, in order to reduce the number of vehicles on the road. This plan can reduce the consumption of energy obtained through burning of fossil fuels and further more reduce carbon dioxide emissions. This approach has the potential to reduce the amount of energy consumed by burning fossil fuels while also lowering carbon dioxide emissions [36]. Furthermore, there was no discernible variation in MET amongst modes of campus mobility. According to the findings of the study, students who walked to school had the greatest total MET compared to those who drove, rode motorbikes, or used buses [37].

There was no significant variation in sleep quality with the sociodemographic variables investigated in this study, according to the findings. When comparing the average sleep quality score by gender and year of study, however, year 4 students and male students had higher average sleep scores, suggesting poor sleep quality. This might be due to engagement in a variety of activities that must be completed prior to graduation, such as a final year research project, clinical training, or industrial training. The findings of this study are similar to those of a study conducted among Saudi medical students, which found no significant relationship between sleep quality and gender or academic year, but found a strong link between sleep quality and stress levels [38]. This indicates that good sleep quality is crucial for reducing stress levels so that they may fully concentrate in class and improve their academic performance and overall quality of life. This research's findings contrast those of a Romanian student study. According to that study, sleep quality varies by study year, with the first year having the largest percentage of good sleep. The study also discovered that PA levels are related to sleep quality, implying that PA is required for healthy sleep [39]. 
Physical activity had no significant correlations with BMI, WC, or blood pressure, according to the findings. However, the results also showed significant correlation between BMI with SBP and DBP. This is similar to another research among Indian people in which there was a positive link between BMI and blood pressure, as BMI was greater among obese individuals and contributed to higher blood pressure [40]. In this study, it was reported that, in the obese category with WC outside of the normal range recorded the greatest number of MET. This could be due to overreporting of self-report physical activity measures. A recent study found that even when people overreporting of the series of physical activity [41], other variables such as an unhealthy diet, a sedentary lifestyle, and other factors might raise BMI and WC [42]. Despite the data being divided into BMI categories of underweight, normal, overweight, and obese, our findings showed that PA had no significant relationship with BMI. The greatest proportion PA group was moderate, according to the descriptive data. This revealed that the majority of the students in this study, regardless of their BMI, engage in moderate physical activity. The piecewise regression revealed that obese students were divided into two groups based on their PA levels: low and moderate. This finding is consistent with the findings of another study conducted in the United States, which found that students in the obese group had a greater risk of not meeting the required PA [43]. Other variables that contribute to obesity include television viewing [43] and eating behaviours such as consuming carbonated beverages while playing video games [44].

Furthermore, while there was no association between sleep quality and BMI or waist circumference, there was an association between blood pressure and BMI. Sleep quality was poor in all groups of BMI and WC. The findings are consistent with earlier research, which found that each hour of sleep deprivation raises the risk of obesity by $80 \%$ [45]. According to previous study poor sleep quality can contribute to an increase in WC [46]. This is also consistent with other research, which show that the greater the average WC, the higher the BMI [47]. Students with high blood pressure have a higher sleep quality score. Although there is no obvious explanation for elevated blood pressure when a person does not get enough sleep, some studies have shown that a lack of sleep can lead to metabolic incompatibility, which is a risk factor for cardiovascular disease [48].

The study also aimed to see if there is an association between physical activity and sleep quality, BMI, and blood pressure. The logistic regression results indicated that BMI among moderate PA students was significantly lower compared to the low PA category. This demonstrates that there is significant relationship between the PA and BMI in the moderate PA group, while there was no significant relationship with other anthropometric measurements and blood pressure [34]. The findings contradict those of a recent study that found an association between physical activity, BMI, and blood pressure in children aged 8 to 18 [49].

The study's main limitation was that it was cross-sectional and thus we could not determine the cause(s) and impact of physical exercise. The findings of this study are also based on university students and cannot be applied to the broader population. The research also lacks biochemical markers such as cholesterol, glucose, and triglycerides, which might be useful in interpreting the health condition of university students. Activity data was also self-reported, so to address the possibility of overreporting of physical activity among university students, it may be proposed that pedometers or accelerometers be utilized in future research. Other variables such as food consumption, body fat distribution, cholesterol level, muscle mass, total energy intake and stress level should also be investigated in the future, as this study has certain limitations in those aspects.

\section{Conclusions}

This study's findings indicate in general, that university students are moderately active. Male students, those studying in first year and with lower BMI recorded greater physical activity levels. The relevance of physical exercise in terms of sleep quality, blood pressure, and anthropometric measures were also emphasized, implying that university 
students should engage in physical activity even if they have a busy schedule in their daily activities. The findings of this study may also recommend to public health practitioners and policymakers that young adults be encouraged to be physically active by launching an awareness campaign using flyers and social media about convenient physical activities they may undertake at home and on campus. Future study should explore at a large sample size and incorporate variables including body fat, muscle mass, stress levels, and energy intake.

Author Contributions: Conceptualization: N.Z.M.S.; methodology: N.Z.M.S. and N.M.F.F.; formal analysis S.A.H., Validatiom: H.M.A. and H.H.; investigation: N.Z.M.S. and T.S., formal analysis: N.Z.M.S., S.A.H. and H.H.; data curation S.A.H. and H.M.A.; writing and review editing: N.Z.M.S. and T.S. supervison: N.Z.M.S. and N.M.F.F.: project administration: N.Z.M.S. and N.M.F.F.; funding acquisition: N.Z.M.S., S.A.H., H.M.A., H.H. All authors have read and agreed to the published version of the manuscript.

Funding: This research received no external.

Institutional Review Board Statement: Not applicable.

Informed Consent Statement: Participants in this study provided informed consent.

Data Availability Statement: The data is available upon request from correspondence author.

Acknowledgments: The authors would like to express their gratitude to CRIM and the Faculty of Health Sciences UKM for their financial assistance with the publication fee. The authors would also like to express their appreciation to Universiti Kebangsaan Malaysia for providing financial assistance with the publication fee under the research grant GGP-2020-024. We also wanted to extend our thanks to Zalina Mohd Ali for her statistical analysis advice.

Conflicts of Interest: The authors declared no conflict of interest.

\section{References}

1. Negi, P.C.; Chauhan, R.; Rana, V.; Lal, K. Epidemiological study of non-communicable diseases (NCD) risk factors in tribal district of Kinnaur, HP: A cross-sectional study. Indian Heart J. 2016, 68, 655-662. [CrossRef]

2. Leiva, A.M.; Martínez, M.A.; Cristi-Montero, C.; Salas, C.; Ramírez-Campillo, R.; Martínez, X.D.; Aguilar-Farías, N.; Celis-Morales, C. Sedentary lifestyle is associated with metabolic and cardiovascular risk factors independent of physical activity. Rev. Méd. Chile 2017, 145, 458-467. [CrossRef] [PubMed]

3. Bennett, J.E.; A Stevens, G.; Mathers, C.D.; Bonita, R.; Rehm, J.; E Kruk, M.; Riley, L.M.; Dain, K.; Kengne, A.P.; Chalkidou, K.; et al. NCD Countdown 2030: Worldwide trends in non-communicable disease mortality and progress towards Sustainable Development Goal target 3.4. Lancet 2018, 392, 1072-1088. [CrossRef]

4. Institute for Public Health. National Health and Morbidity Survey (NHMS) 2015: Volume 1: Methodology and General Findings; Ministry of Health Malaysia: Kuala Lumpur, Malaysia, 2015.

5. Fedewa, A.L.; Ahn, S. The Effects of Physical Activity and Physical Fitness on Children's Achievement and Cognitive Outcomes: A meta-analysis. Res. Q. Exerc. Sport 2011, 82, 521-535. [CrossRef]

6. Hanawi, S.A.; Saat, N.Z.; Zulkafly, M.; Hazlenah, H.; Taibukahn, N.H.; Yoganathan, D.; Abdul Rahim, N.N.; Mohd Bashid, N.A.; Abdul Aziz, F.A.; Low, F.J. Impact of a Healthy Lifestyle on the Psychological Well-being of University Students. Int. J. Pharm. Res. Allied Sci. 2020, 9. Available online: https://ijpras.com/article/positive-effects-of-residence-challenges-the-impact-of-beingsuccessful-on-academic-achievement-of0gqa7bsbrelj6?html (accessed on 12 July 2021).

7. Peterson, N.E.; Sirard, J.R.; Kulbok, P.A.; DeBoer, M.D.; Erickson, J.M. Sedentary behavior and physical activity of young adult uni-versity students. Res. Nurs. Health 2018, 41,30-38. [CrossRef]

8. Mogre, V.; Nyaba, R.; Aleyira, S.; Sam, N.B. Demographic, dietary and physical activity predictors of general and abdominal obesity among university students: A cross-sectional study. SpringerPlus 2015, 4, 1-8. [CrossRef]

9. Papathanasiou, G.; Zerva, E.; Zacharis, I.; Papandreou, M.; Papageorgiou, E.; Tzima, C.; Georgakopoulos, D.; Evangelou, A. Association of High Blood Pressure with Body Mass Index, Smoking and Physical Activity in Healthy Young Adults. Open Cardiovasc. Med. J. 2015, 9, 5-17. [CrossRef] [PubMed]

10. Lachman, S.; Boekholdt, S.M.; Luben, R.N.; Sharp, S.J.; Brage, S.; Khaw, K.-T.; Peters, R.J.; Wareham, N.J. Impact of physical activity on the risk of cardiovascular disease in middle-aged and older adults: EPIC Norfolk prospective population study. Eur. J. Prev. Cardiol. 2017, 25, 200-208. [CrossRef]

11. Kraus, W.E.; Powell, K.E.; Haskell, W.L.; Janz, K.F.; Campbell, W.W.; Jakicic, J.M.; Troiano, R.; Sprow, K.; Torres, A.; Piercy, K.L. Physical Activity, All-Cause and Cardiovascular Mortality, and Cardiovascular Disease. Med. Sci. Sports Exerc. 2019, 51, 1270-1281. [CrossRef] 
12. Mahfouz, M.S.; Ali, S.A.; Bahari, A.Y.; Ajeebi, R.E.; Sabei, H.J.; Somaily, S.Y.; Madkhali, Y.A.; Hrooby, R.H.; Shook, R.N. Association Between Sleep Quality and Physical Activity in Saudi Arabian University Students. Nat. Sci. Sleep 2020, 12, 775-782. [CrossRef]

13. Feng, Q.; Zhang, Q.-L.; Du, Y.; Ye, Y.-L.; He, Q.-Q. Associations of Physical Activity, Screen Time with Depression, Anxiety and Sleep Quality among Chinese College Freshmen. PLoS ONE 2014, 9, e100914. [CrossRef]

14. Arbinaga, F.; Fernández-Cuenca, S.; Fernández-Ozcorta, E.J.; Toscano-Hermoso, M.D.; Joaquin-Mingorance, M. Level of physical activity and sleep characteristics in university students. Sleep Sci. 2020, 12, 265-271. [CrossRef]

15. Institute for Public Health. National Health and Morbidity Survey (NHMS) 2019: Non-Communicable Diseases, Healthcare Demand, and Health Literacy -Key Findings Shah Alam, Selangor; Institute for Public Health: Bilthoven, The Netherlands, 2020.

16. Ministry of Health Malaysia National Strategic Plan for Non-Communicable Disease (NSP-NCD) 2016-2025. 2016. Available online: https:/ / www.moh.gov.my/moh/resources/Penerbitan/Rujukan/NCD/National\%20Strategic\%20Plan/FINAL_ NSPNCD.pdf (accessed on 8 October 2021).

17. Cochran, W.G. Sampling Techniques, 2nd ed.; John Wiley and Sons, Inc.: New York, NY, USA, 1963.

18. Zulkepli, Z.; Zakiah, N.; Nor Farah, M.F.; Hanawi, S.A.; Zin, N.M. Relationship between physical activity level and cardiovascular risk factors among teachers. Asian J. Epidemiol. 2019, 12, 1-8. [CrossRef]

19. World Health Organization (WHO). Appropriate body-mass index for Asian populations and its implications for pol-icy and intervention strategies. Lancet 2004, 363, 157-166. [CrossRef]

20. World Health Organization. Waist Circumference and Waist-Hip Ratio: Report of a WHO Expert Consultation, Geneva, 8-11 December 2008. Available online: https:/ /www.who.int/publications/i/item/9789241501491 (accessed on 9 October 2021).

21. Hassan, M.R.; Ahmad, N.; Adam, S.I.M.; Nawi, A.M.; Ghazi, H.F. Abdominal obesity indicators: Waist circumference or waist-to-hip ratio in Malaysian adults population. Int. J. Prev. Med. 2016, 7, 82. [CrossRef]

22. Zainudin, S.; Daud, Z.; Mohamad, M.; Boon, A.T.T.; Mohamed, W.M.I.W. A Summary of the Malaysian Clinical Practice Guidelines on Management of Obesity 2004. J. ASEAN Fed. Endocr. Soc. 2011, 26, 101-104. [CrossRef]

23. Kshirsagar, A.V.; Carpenter, M.; Bang, H.; Wyatt, S.B.; Colindres, R.E. Blood Pressure Usually Considered Normal Is Associated with an Elevated Risk of Cardiovascular Disease. Am. J. Med. 2006, 119, 133-141. [CrossRef]

24. IPAQ. Guidelines for Data Processing and Analysis of the International Physical Activity Questionnaire (IPAQ)-Short and Long Forms, Revised on November 2005. Available online: https://docs.google.com $/$ viewer?a=v\&pid=sites\&srcid= ZGVmYXVsdGRvbWFpbnxaGVpcGFxfGd4OjE0NDgxMDk3NDU1YWR1ZTM (accessed on 15 October 2019).

25. Saat, N.Z.M.; Hanawi, S.A.; Chan, K.S.; Hanafiah, H.; Teh, S.C.; Aznan, S.R.; Joan, C.; Ahmad, S.; Zulkefli, Z.H. Sleep Quality among University Students: Associations between Demographic Factors and Physical Activity Level. Int. J. Pharm. Res. Allied Sci. 2020, 9. Available online: https:/ /ijpras.com/article/sleep-quality-among-university-students-associations-betweendemographic-factors-and-physical-activity-level (accessed on 12 July 2021).

26. Aris, A.; Khalid, M.Z.M.; Yahaya, H.; Yoong, L.O.; Ying, N.Q.; Zulhilmy, M. Type 2 Diabetes Risk Among University Students in Malaysia. Curr. Diabetes Rev. 2020, 16, 387-394. [CrossRef]

27. Buysse, D.J.; Reynolds, C.F.; Monk, T.H.; Berman, S.R.; Kupfer, D.J. The Pittsburgh sleep quality index: A new instrument for psychiatric practice and research. Psychiatry Res. 1989, 28, 193-213. [CrossRef]

28. Tek, N.A.; Mortas, H.; Arslan, S.; Tatar, T.; Köse, S. The physical activity level is low in young adults: A pilot study from Turkey. Am. J. Public Health Res. 2020, 8, 7-13. [CrossRef]

29. Dan, S.P.; Mohd, N.M.T.; Zalilah, M.S. Determination of factors associated with physical activity levels among adolescents attending school in Kuantan, Malaysia. Malays. J. Nutr. 2011, 17, 175-187. Available online: https://nutriweb.org.my/mjn/ publication/17-2/d.pdf (accessed on 8 October 2021).

30. Bergier, J.; Tsos, A.; Popovych, D.; Bergier, B.; Niźnikowska, E.; Ács, P.; Junger, J.; Salonna, F. Level of and Factors Determining Physical Activity in Students in Ukraine and the Visegrad Countries. Int. J. Environ. Res. Public Health 2018, 15, 1738. [CrossRef] [PubMed]

31. Rajappan, R.; Selvaganapathy, K.; Liew, L. Physical activity level among university students: A cross sectional survey. Int. J. Physiother. Res. 2015, 3, 1336-1343. [CrossRef]

32. Saat, N.Z.M.; Ishak, I.; Lubis, S.H.; Ghazali, A.R. The Effect of Merit Score Towards the Stress Score Among First Year Student. Procedia Soc. Behav. Sci. 2011, 18, 613-616. [CrossRef]

33. Micalos, P.S.; MacQuarrie, A.J.; Haskins, B.A.; Barry, E.; Anderson, J. Evaluation of the health and physical activity characteristics of undergraduate paramedic and nursing students. Australas. J. Paramed. 2017, 14. [CrossRef]

34. Alhaqbani, A.S.; AlMaini, R.Y.; Alshalhoub, M.Z.; Mcrabi, A.H.; Marenga, A.S.; Omair, A.A. Appraising the degree of physical activities among male students at a Saudi medical school. J. Taibah Univ. Med Sci. 2020, 15, 417-421. [CrossRef]

35. Mitáš, J.; Cerin, E.; Reis, R.S.; Conway, T.L.; Cain, K.L.; Adams, M.A.; Schofield, G.; Sarmiento, O.L.; Christiansen, L.B.; Davey, R.; et al. Do associations of sex, age and education with transport and leisure-time physical activity differ across 17 cities in 12 countries? Int. J. Behav. Nutr. Phys. Act. 2019, 16, 1-12. [CrossRef]

36. Figueiredo, N.; Rodrigues, F.; Morouço, P.; Monteiro, D. Active Commuting: An Opportunity to Fight Both Climate Change and Physical Inactivity. Sustainability 2021, 13, 4290. [CrossRef]

37. Adams, J. Prevalence and socio-demographic correlates of "active transport" in the UK: Analysis of the UK time use survey 2005. Prev. Med. 2010, 50, 199-203. [CrossRef] 
38. Almojali, A.I.; Almalki, S.A.; Alothman, A.S.; Masuadi, E.; Alaqeel, M.K. The prevalence and association of stress with sleep quality among medical students. J. Epidemiol. Glob. Health 2017, 7, 169-174. [CrossRef]

39. Badicu, G. Physical Activity and Sleep Quality in Students of the Faculty of Physical Education and Sport of Braşov, Romania. Sustainability 2018, 10, 2410. [CrossRef]

40. Mungreiphy, N.K.; Kapoor, S.; Sinha, R. Association between BMI, Blood Pressure, and Age: Study among Tangkhul Naga Tribal Males of Northeast India. J. Anthropol. 2011, 2011, 1-6. [CrossRef]

41. Winckers, A.N.E.; MacKenbach, J.D.; Compernolle, S.; Nicolaou, M.; Van Der Ploeg, H.P.; De Bourdeaudhuij, I.; Brug, J.; Lakerveld, J.; Winckers, A.N.E.; MacKenbach, J.D.; et al. Educational differences in the validity of self-reported physical activity. BMC Public Health 2015, 15, 1-5. [CrossRef]

42. Sham, F.M. Stress Symptoms Among Adolescent: A Study from Islamic Perspective. J. Relig. Health 2014, 54, 1278-1285. [CrossRef]

43. Pérez, A.; Hoelscher, D.; Springer, A.E.; Brown, H.S.; Kelder, S.H.; Barroso, C.S.; Castrucci, B.C. Physical Activity, Watching Television, and the Risk of Obesity in Students, Texas, 2004-2005. Prev. Chronic Dis. 2011, 8, A61.

44. Syed, N.K.; Syed, M.H.; Meraya, A.M.; Albarraq, A.A.; Al-Kasim, M.A.; Alqahtani, S.; Makeen, H.A.; Yasmeen, A.; Banji, O.J.F.; Elnaem, M.H. The association of dietary behaviors and practices with overweight and obesity parameters among Saudi university students. PLOS ONE 2020, 15, e0238458. [CrossRef]

45. Gupta, N.K.; Mueller, W.H.; Chan, W.; Meininger, J.C. Is obesity associated with poor sleep quality in adolescents? Am. J. Hum. Biol. 2002, 14, 762-768. [CrossRef]

46. Jennings, J.R.; Muldoon, M.F.; Hall, M.; Buysse, D.J.; Manuck, S.B. Self-reported Sleep Quality is Associated with the Metabolic Syndrome. Sleep 2007, 30, 219-223. [CrossRef] [PubMed]

47. Zhu, S.; Heshka, S.; Wang, Z.; Shen, W.; Allison, D.B.; Ross, R.; Heymsfield, S.B. Combination of BMI and Waist Circumference for Identifying Cardiovascular Risk Factors in Whites. Obes. Res. 2004, 12, 633-645. [CrossRef] [PubMed]

48. Cizza, G.; Skarulis, M.; Mignot, E. A Link Between Short Sleep and Obesity: Building the Evidence for Causation. Sleep 2005, 28, 1217-1220. [CrossRef] [PubMed]

49. Betz, H.H.; Eisenmann, J.C.; Laurson, K.R.; DuBose, K.D.; Reeves, M.J.; Carlson, J.J.; Pfeiffer, K.A. Physical Activity, BMI, and Blood Pressure in US Youth: NHANES 2003-2006. Pediatr. Exerc. Sci. 2018, 30, 418-425. [CrossRef] [PubMed] 